\title{
Comparative Immature Morphology of Brazilian Fire Ants (Hymenoptera: Formicidae: Solenopsis)
}

\author{
Eduardo Gonçalves Paterson Fox, ${ }^{1}$ Daniel Russ Solis, ${ }^{2}$ Mônica Lanzoni Rossi, ${ }^{3}$ \\ Jacques Hubert Charles Delabie, ${ }^{4}$ Rodrigo Fernando de Souza, ${ }^{2}$ and Odair Correa Bueno ${ }^{2}$ \\ ${ }^{1}$ Laboratório de Entomologia Médica, Centro de Ciências da Saúde, Federal University of Rio de Janeiro (UFRJ), \\ 21.945-970 Ilha do Fundão, RN, Brazil \\ ${ }^{2}$ Centro de Estudos de Insetos Sociais, Instituto de Biociências, Sao Paulo State University (UNESP), 13506-900 Rio Claro, SP, Brazil \\ ${ }^{3}$ Laboratório de Histopatologia e Biologia Estrutural de Plantas, Centro de Energia Nuclear na Agricultura, \\ University of São Paulo (USP), 13400-970 Piracicaba, SP, Brazil \\ ${ }^{4}$ Laboratório de Mirmecologia, Centro de Pesquisa do Cacau, 45650-000 Itabuna, BA, Brazil
}

Correspondence should be addressed to Eduardo Gonçalves Paterson Fox, ofoxofox@gmail.com

Received 18 March 2011; Accepted 29 April 2011

Academic Editor: Fernando Fernández

Copyright (C) 2012 Eduardo Gonçalves Paterson Fox et al. This is an open access article distributed under the Creative Commons Attribution License, which permits unrestricted use, distribution, and reproduction in any medium, provided the original work is properly cited.

\begin{abstract}
Although common in Brazil, the biology of the fire ant Solenopsis saevissima (Smith) is still poorly studied. Larval descriptions are useful to genus-level ant systematics and sometimes to species-level taxonomy. This study presents a detailed description of juveniles of S. saevissima from Brazil, which were compared with Brazilian specimens of Solenopsis invicta Buren, Solenopsis geminata (Fabricius), and Solenopsis altipunctata Pitts. Different larval instars were separated by diagnostic morphological traits which were confirmed by observing moults. Reproductive larvae could be easily sorted by their distinctive body dimensions and shape. Contrary to previous reports on this species, the larvae of S. saevissima proved to be generally identical to those of S. invicta, while a few specimens resembled those of other close species, such as Solenopsis megergates Trager. Mature larvae thus presented considerable intraspecific variation in some characters recently proposed to aid fire ant species separation (morphology of head hairs).
\end{abstract}

\section{Introduction}

The importance of immature morphology to insect systematics and taxonomy was extensively discussed in previous studies [1-3]. The present investigation is part of a series of studies on ant larvae which attempt to remedy the limitations in the available morphological information on immature ant morphology.

Solenopsis (Hymenoptera: Formicidae) is a cosmopolitan ant genus that includes approximately 300 species, of which over 108 occur in the New World [4]. Some of the largest species are aggressive, polymorphic ants commonly known as "fire ants" that are usually harmful in both their native and invasive geographical ranges. The Solenopsis saevissima species group (sensu [5]) includes some 13 species of fire ants which are markedly difficult to identify because of the plasticity of morphological characters, and because of their strong polymorphism. In an attempt to propose a phylogenetic hypothesis for species within the complex, Pitts et al. [5] revisited the morphological characters as originally proposed by Trager [6] and added new ones, including the use of head setae of last-instar larvae. Of the fire ant species analysed in his study, there are published larval descriptions only for S. invicta and S. geminata [7-9].

The fire ant Solenopsis saevissima Smith is widespread and common in Brazil, however still remains a generally poorly studied species. Their larvae are undescribed. Recently, a broad genetic study [10] demonstrated that it comprises a number of cryptic species along the Brazilian coast. This prompted the question of whether or not larvae of geographically distant populations of S. saevissima would be morphologically identical. The goal of the present study 
was to describe each immature stage of S. saevissima obtained from three distant localities, as well as to compare these larvae with specimens of Solenopsis invicta Buren, Solenopsis geminata (Fabricius), and Solenopsis altipunctata Pitts from Brazil.

\section{Material and Methods}

2.1. Collection of Samples. Whole nests of S. saevissima were obtained from three different localities in Brazil: (1) Pouso Alegre, Minas Gerais (MG) $\left(22^{\circ} 13^{\prime} \mathrm{S}, 45^{\circ} 56^{\prime} \mathrm{W}\right)$, (2) Pedro do Rio, Rio de Janeiro (RJ) $\left(22^{\circ} 20^{\prime} \mathrm{S}, 43^{\circ} 7^{\prime} \mathrm{W}\right)$, and (3) Ilhéus, Bahia (BA) $\left(14^{\circ} 15^{\prime} \mathrm{S}, 39^{\circ} 13^{\prime} \mathrm{W}\right)$. In addition, whole nests of S. geminata were obtained at site (3); S. invicta was obtained from Rio Claro, São Paulo (SP) $\left(22^{\circ} 23^{\prime} \mathrm{S}\right.$, $47^{\circ} 32^{\prime} \mathrm{W}$ ) and at site (2); and S. altipunctata was obtained at site (2). Species identification was based on Trager [6] and Pitts et al. [5]; only "typical" morphs were used, that is, those clearly presenting the following set of characters. Solenopsis saevissima: a poorly developed central clypeal tooth, lack of a medial frontal streak, and absence of a frontal ocellus; S. geminata: all mentioned characters plus major workers with characteristically cordate enlarged heads, lacking the central clypeal tooth, and bearing shorter scapes and blunt mandibles; S. invicta: well-developed clypeal tooth and carinae, evident medial frontal streak, and absence of a frontal ocellus; S. altipunctata: similar to S. invicta, but with central clypeal tooth poorly developed, medial frontal streak feeble, and anterior wings of queens with medial cell open.

DNA was extracted and mtDNA sequencing followed the same methods described by Ross et al. [10], confirming species identifications. Species identification was corroborated using chemical characters (venom alkaloids and cuticular hydrocarbons) as described in a separate publication.

Voucher specimens of all immature and adult stages of the collected nests were deposited in the entomological collections of Instituto Biológico and Museu de Zoologia (MZUSP), SP, Brazil.

2.2. Determination of Larval Instars. The first instar and the last instar can be directly identified as hatching larvae and prepupae, and thus be used as reference to determine others. Other distinct instar characteristics used were based on Petralia and Vinson [9]. Larval instar characteristics were further validated during the descriptions from observing moulting larvae.

2.3. Differentiation of Larvae from Different Castes. Worker larvae only differed when mature in bodily dimensions, thus a size interval is given. Gyne and male larvae were considerably larger than worker larvae and presented typical body shapes of their own. These were directly confirmed as they moulted into male or female alate pupae.

2.4. Description of the Immature Forms. All collected samples were fixed in Dietrich's solution $(900 \mathrm{~mL}$ distilled water, $450 \mathrm{~mL} 95 \%$ ethanol, $150 \mathrm{~mL} 40 \%$ formaldehyde, $30 \mathrm{~mL}$ acetic acid) for $24 \mathrm{~h}$, and then preserved in $70 \%$ alcohol.
Samples to be analysed under the scanning electron microscope were dehydrated in an alcohol graded series (80100\%; a 10-min-dip for each concentration), and criticalpoint dried (Balzers CPD/030). Dried specimens were then attached to aluminium stubs with double-faced conductive adhesive tape and gold-sputtered with a Balzers SCD/050 sputterer. Observations and images were obtained as soon as possible after sample preparation. Samples to be analysed under the compound microscope were warmed for $15 \mathrm{~min}$ in $\mathrm{KOH} 10 \%$ and placed in a small drop of glycerin on a microscope slide.

The morphological descriptions were based on over 10 larvae of each instar. The larvae were analyzed and described under a compound light microscope (Zeiss MC80 DX, with maximum magnification of 1000x), and illustrations were obtained with a scanning electron microscope (LEO $435 \mathrm{VP}$, at $20.0 \mathrm{kV}$ ). With a stereomicroscope (Zeiss Stemi SV11, with maximum magnification of 66x) equipped with a micrometric eyepiece, we obtained measures of every stage. All terminology used herein follows G. C. Wheeler and J. Wheeler [2], and measures are given either as approximate measures, size intervals, or mean $\pm \mathrm{SD}$ followed by the number $(n)$ of individuals analyzed, depending on sample size. Further specimens were later mounted on glass slides to rapidly check for intraspecific variations.

2.5. Comparison with Other Samples. Last instar larvae of the following species were also rapidly analyzed for intraspecific variations: S. invicta from SP and RJ, S. altipunctata from RJ, and S. geminata from BA.

\section{Results}

3.1. Identification of Cryptic Species within S. saevissima. Mitochondrial DNA sequences were compared with accessions from the National Center for Biotechnology Information (NCBI/GenBank). Two of the three samples of S. saevissima could be amplified-BA and RJ-no sequences were recovered from MG. Their haplotypes were, respectively, W11 and W51, thus belonging to two different cryptic populations (refer to NCBI for further details on the haplotypes), and displayed different sets of cuticular hydrocarbons (not shown). Larvae of the different populations of S. saevissima proved identical, and are jointly described below.

\subsection{Immature Morphology of Solenopsis saevissima}

(Smith, 1855)

3.2.1. Egg (Figure 1(a)). Widely ovoid in shape, about $0.18 \mathrm{~mm} \times 0.25 \mathrm{~mm}$, with whitish embryo showing through the transparent chorion. No outer ornamentation or orifices (Figure 1(a)). Eclosion by medial transverse rupture (Figure 1(b)), when first-instar larva outgrows chorion.

3.2.2. First Larval Instar (Figures $1(c)-1(f)$ ). Body profile attoid, defined in [2] as: very short, stout, and curved, with segmentation indistinct; "diameter approximately equal to distance from labium to anus; anus being terminal." 


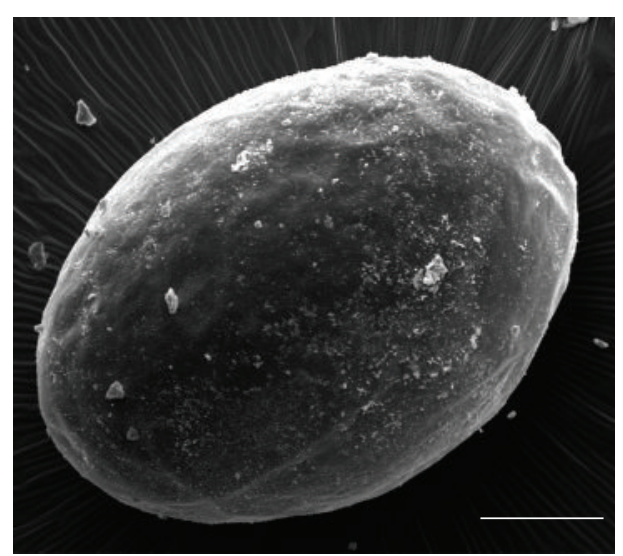

(a)

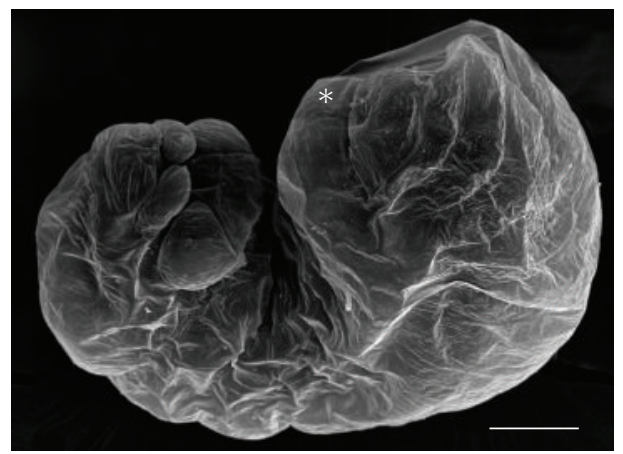

(c)

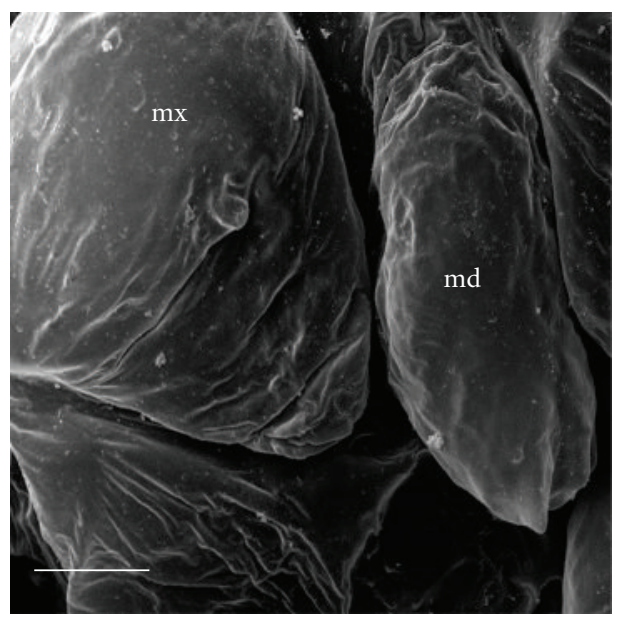

(e)

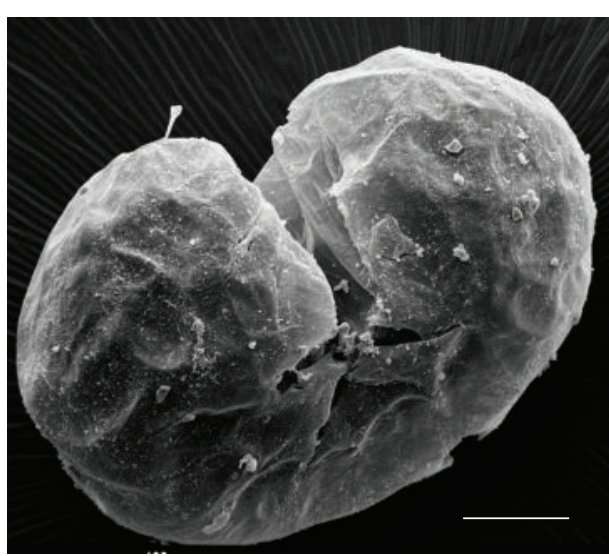

(b)

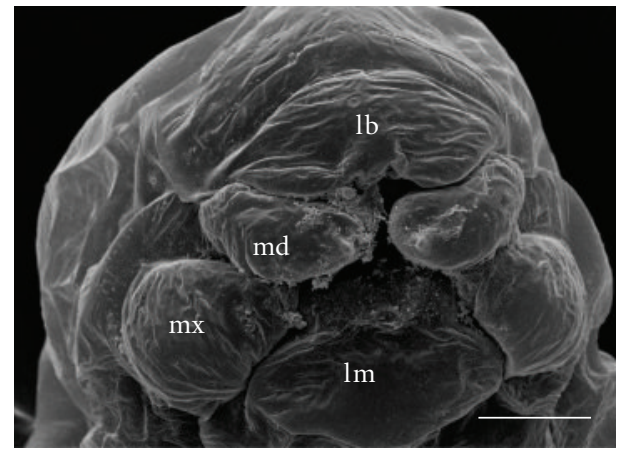

(d)

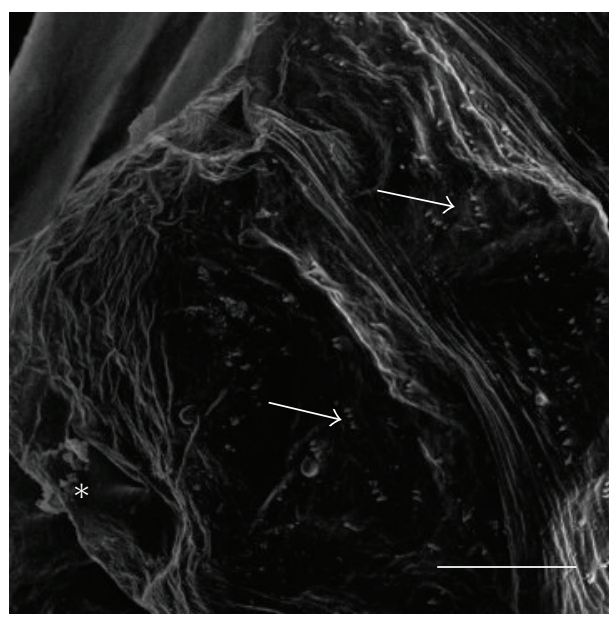

(f)

FIgURE 1: Egg and first instar larva of Solenopsis saevissima. (a) Egg. (b) Hatching larva. (c) Oblique view of first instar larva; inset: thoracic spiracle. (d) Head capsule and mouthparts; lb: labrum; md: mandible; mx: maxilla; lm: labium. (e) Detail of mouthparts, showing right maxilla and mandible. (f) Terminal region of body, showing anus (asterisk) and rows of spinules (setae). Respective sizes of scale bars ( $\mu \mathrm{m}$ ): $50,25,50,20,10$, and 15 .

Body about $0.290-0.340 \mathrm{~mm}$ long $\times 0.140-0.160 \mathrm{~mm}$ wide $(n=5)$; body length through spiracles $0.520 \mathrm{~mm}(n=$ 1) (Figure 1(c)). Ten inconspicuous pairs of spiracles, first one larger in diameter $(0.002 \mathrm{~mm})$ than others $(0.001 \mathrm{~mm})$. Integument surface smooth, without setation (Figure 1(c)), however with short spines over posterior abdominal region and around anus (Figure 1(f)). Head capsule subelliptical,
$0.120-0.140 \mathrm{~mm}$ wide $(n=5)$, without setation or sensilla (Figure 1(d)). Clypeus and labrum fused to a single semicircular structure $(0.035 \mathrm{~mm}$ wide) (Figure $1(\mathrm{~d}))$; mandibles round and transparent, with two short apical teeth, about $0.025 \mathrm{~mm}$ long and $0.018 \mathrm{~mm}$ wide $(n=2$; Figure $1(\mathrm{e}))$. Maxillae lobose about $0.020 \mathrm{~mm}$ long and $0.020 \mathrm{~mm}$ wide $(n=1)$; maxillary palps and galea indistinct (Figure 1(e)). 


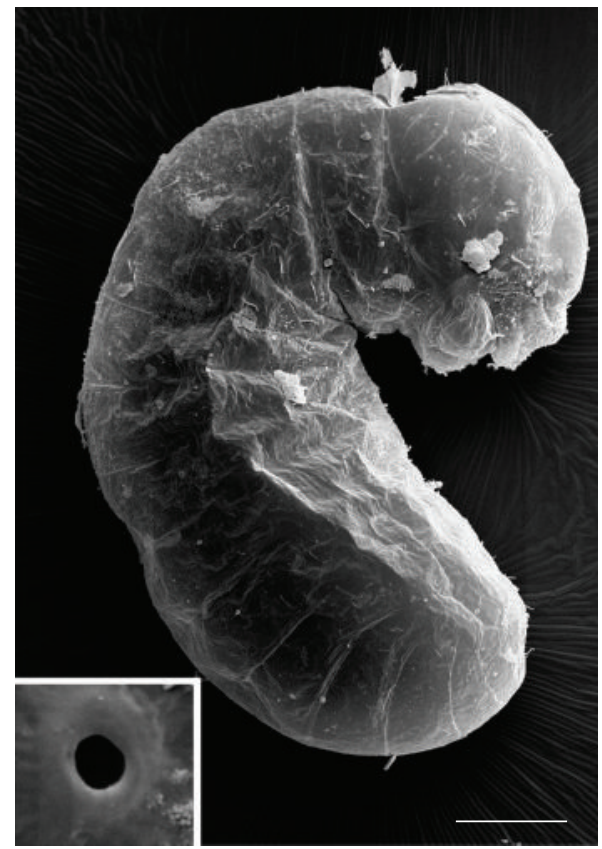

(a)

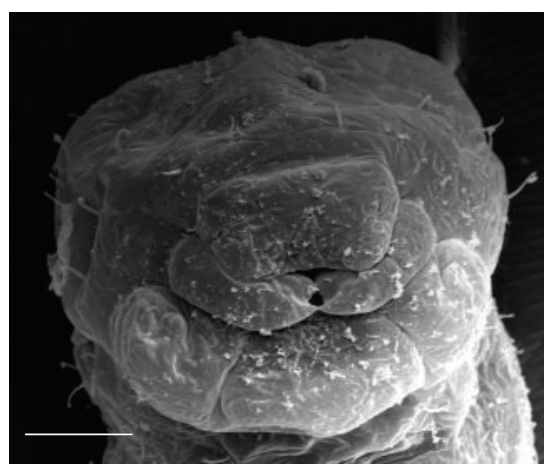

(b)

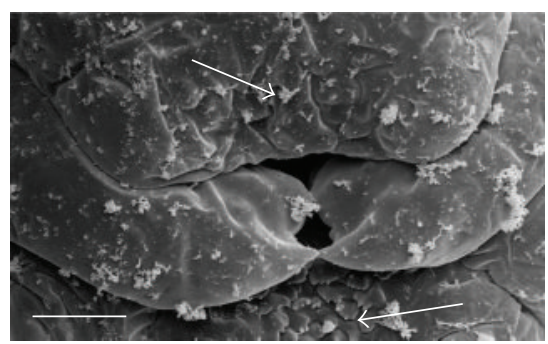

(c)

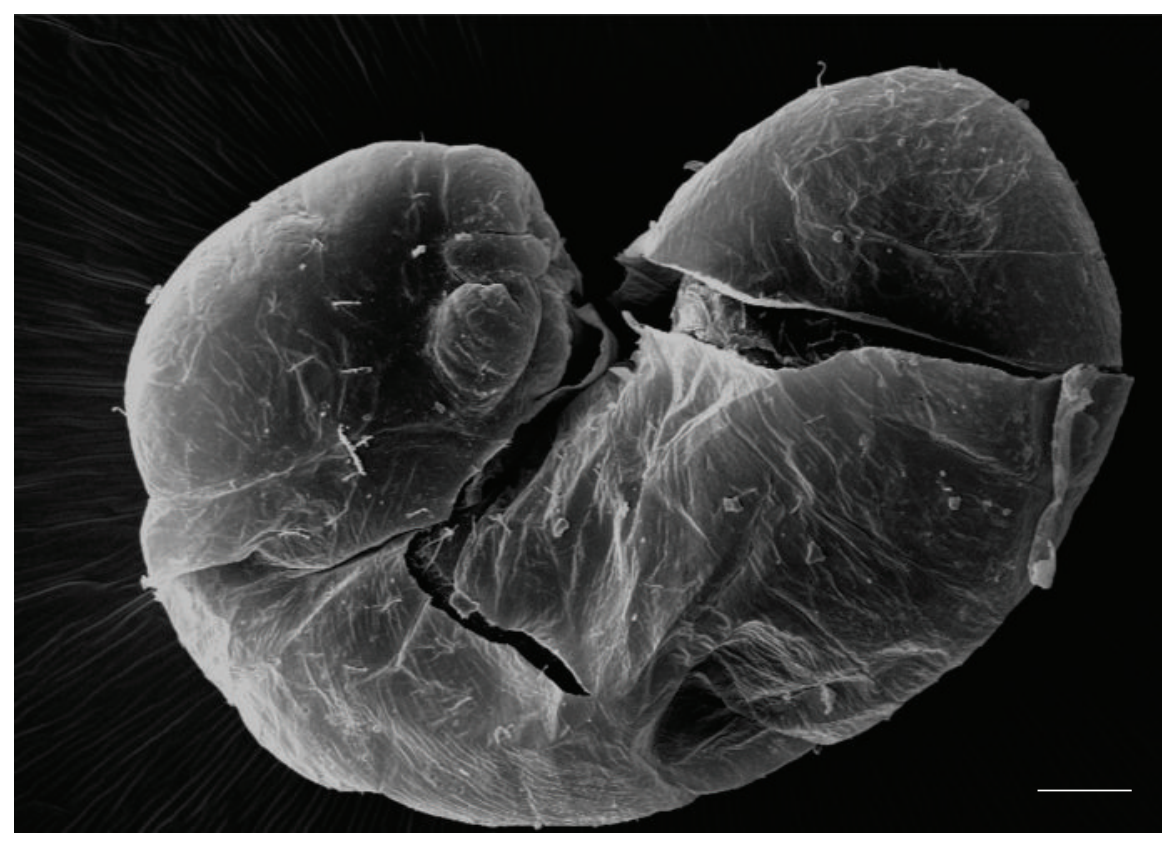

(d)

FIGURE 2: Second instar larva of Solenopsis saevissima. (a) Larva on side view; inset: thoracic spiracle. (b) Head capsule. (c) Mouthparts; arrows: spines around mouth entrance. (d) Larva moulting to third instar. Respective sizes of scale bars $(\mu \mathrm{m}): 100,40,15$, and 50.

Labium ovoid, about $0.030 \mathrm{~mm}$ wide $(n=3)$ (Figure $1(\mathrm{~d})$ ); labial palps indistinguishable.

3.2.3. Second Larval Instar (Figures 2(a)-2(d)). Body profile attoid, greatly curved, with anus terminal; $0.480 \pm 0.010 \mathrm{~mm}$ long and $0.230 \pm 0.010 \mathrm{~mm}$ wide at widest somites $(n=$ 9); body length through spiracles $0.640 \mathrm{~mm}(n=1)$ (Figure 2(a)). Body hairs scarce and always simple, 0.026$0.030 \mathrm{~mm}$ long $(n=47)$, concentrated on the dorsal area of the first thoracic somite and over the terminal region of the body (not shown). Ten pairs of unornamented spiracles (inset in Figure 2(a)), first one slightly larger $(0.010 \mathrm{~mm})$ than the rest $(0.006 \mathrm{~mm})(n=7)$. Head capsule subelliptical, $0.150-0.180 \mathrm{~mm}$ wide $(n=9$; Figure $2(\mathrm{~b}))$. Head hairs distributed as follows: between six and eight over the occipital border, two or three on vertex, and five on each gena. Antennae difficult to spot and bearing three basiconic sensilla (not shown). Mouthparts: Clypeus fused 


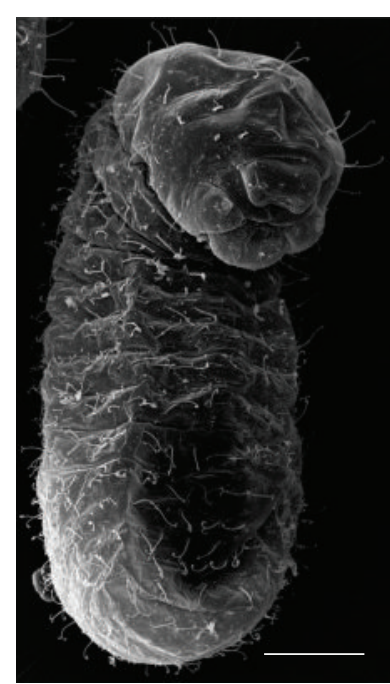

(a)

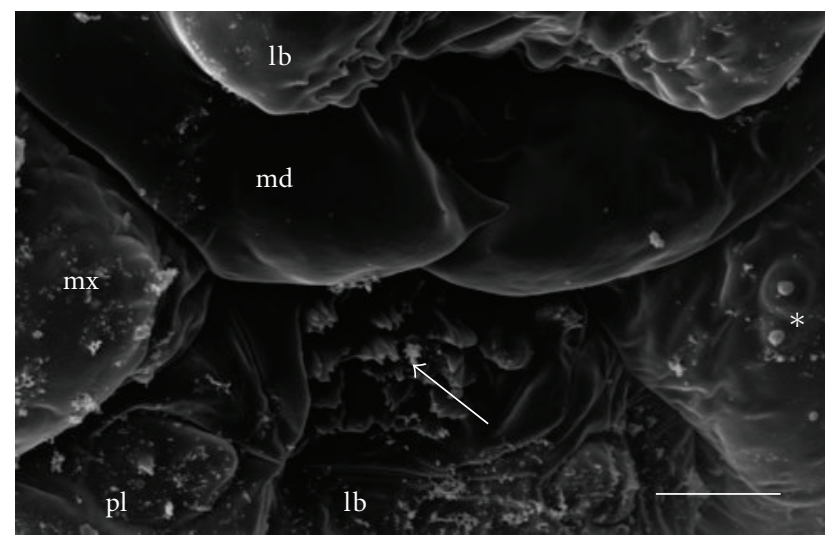

(c)

Figure 3: Third instar larva of Solenopsis saevissima. (a) Larva in frontal view. (b) Larva moulting to fourth instar. (c) Mouthparts; lb: labrum; md: mandible; mx: maxilla; lm: labium; arrow: spiny papillae at mouth entrance; asterisk: galea. Respective sizes of scale bars $(\mu \mathrm{m}): 100,100$, and 10 .

with labrum into a single short trapezoidal structure about $0.080 \mathrm{~mm}$ wide and $0.090 \mathrm{~mm}$ long $(n=2)$, with a row of four simple hairs (Figures 2(b) and 2(d)); spiny papillae on dorsal surface near mouth entrance (Figure 2(c)). Maxillae lobose and $0.049 \mathrm{~mm}$ long and $0.050 \mathrm{~mm}$ wide $(n=$ 2 ), with one simple hair at base (not shown). Mandibles unpigmented and roughly camponotus in shape, yet with pronounced apical tooth and one small subapical tooth; about $0.05 \mathrm{~mm}$ long and $0.033 \mathrm{~mm}$ wide at base $(n=$ 5; Figure 2(c)). Labium a $0.06 \mathrm{~mm}$-wide sphere, no visible palps or spinneret (not shown); densely spinulose near mouth entrance (Figure 2(c)). Moult occurs by apparently random rupture of tegument skin (Figure 2(d)).

3.2.4. Third Larval Instar (Figures 3(a)-3(c)). Body profile roughly dolichoderus, defined in [2] as "short, stout, plump (...) with both ends broadly rounded; anterior end formed by enlarged dorsum of prothorax; head ventral, near anterior end; no neck; somites indistinct." About $1.220 \mathrm{~mm} \pm$ $0.010 \mathrm{~mm}$ long and $0.480 \mathrm{~mm} \pm 0.010 \mathrm{~mm}$ wide $(n=$ $172)$; length through spiracles about $1.300 \mathrm{~mm}(n=2)$ (Figures 3(a) and 3(b)). Body hairs uniformly distributed and of three types: deeply bifid $(0.020-0.03 \mathrm{~mm}$ long), bifid $(0.030 \mathrm{~mm}$ long), and simple, with curved hook-like tips (0.010-0.050 mm long) (Figures 3(a) and 3(b)). Simple hairs predominant, except for ventral region of anterior somites ("food basket" area), which is naked and without spinules (not shown). Bifid hairs also found over most of body surface, but predominant on posterior body region. Ten pairs of spiracles, with the first slightly larger $(0.100 \mathrm{~mm})$ than the rest $(0.070 \mathrm{~mm})(n=26)$. Head capsule $0.280 \pm 0.010 \mathrm{~mm}$ wide $(n=172)$; subelliptical and presenting three types of hairs: simple with tip hooked $(0.040 \mathrm{~mm}$ long $)$, smooth and simple $(0.007 \mathrm{~mm}$ long), and bifid $(0.015-0.020 \mathrm{~mm}$ long) (not shown). Head hairs distributed as follows: six or seven hairs on occipital border, some (up to 1-3) bifurcated in some specimens, five hook-tipped simple hairs, and three or four bifid hairs on the vertex (some specimens had only simple hook-tipped hairs), two or three hook-tipped hairs on frons, five to eight simple hairs on each gena (bifid in some specimens, while one had one 3-branched hair). Antennae slight elevations with three basiconic sensilla (not shown). A conspicuous pair of enclosed sensilla on base of each mandible. Mouthparts (Figure 3(b)): clypeus and labrum fused into a single trapezoidal structure $0.087 \mathrm{~mm}$ wide $(n=6)$, slightly depressed mesad with a row of four simple hairs; four to six setaceous sensilla on anterior face of labrum, and six to seven basiconic sensilla on posterior face of labrum (not shown), the latter densely endowed with spinulose papillae (Figure 3(c)). Maxillae paraboloidal, about $0.050 \mathrm{~mm}$ long and $0.037 \mathrm{~mm}$ wide, with a hook-tipped hair near the base (some specimens with one additional short simple hair) and two setaceous sensilla; maxillary palpus a simple elevation with four basiconic sensilla, and galea represented by a pair of basiconic sensilla (Figure 3(c)). Mandibles poorly sclerotized, about $0.057 \mathrm{~mm}$ long and $0.037 \mathrm{~mm}$ wide at base (Figure 3(c)). Labium elliptical, about $0.1 \mathrm{~mm}$ wide, with one or two setaceous sensilla on the surface below the opening of the sericteries-not shown, an horizontal slit about $0.040 \mathrm{~mm}$-and a conspicuous cluster of spiny papillae towards mouth entrance (Figure 3(c)).

3.2.5. Fourth Larval Instar of Worker (Figures $4(a)-4(d)$ ). Body profile pheidole, defined in [2] as with "abdomen short, stout, and straight; head ventral near anterior end, mounted on short stout neck, which is the prothorax; ends rounded, one end more so than the other." Larvae varying from 1.350 to $2.850 \mathrm{~mm}$ long $(n=77)$ and 0.580 to $1.30 \mathrm{~mm}$ wide $(n=77)$ (Figure $4(\mathrm{a}))$. Dimensions of spiracle peritremes and mandibles of larvae of different sizes always about the same ( $n=20$ specimens of different sizes). All measurements given below were taken from a 3.00-mm-long worker larva, unless stated otherwise. Body length through spiracles $0.630-4.220 \mathrm{~mm}$ ( $n=7$ larvae of different sizes). Body hairs uniformly distributed, of three types: deeply 


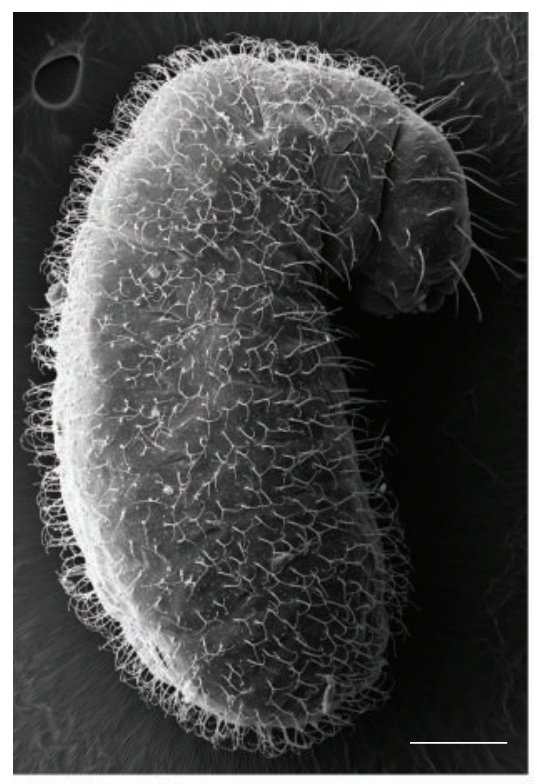

(a)

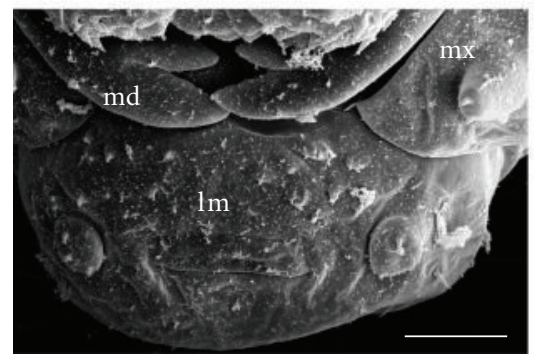

(d)

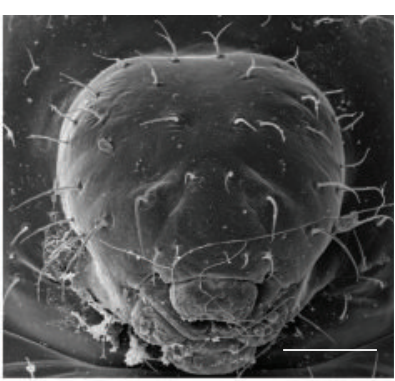

(b)

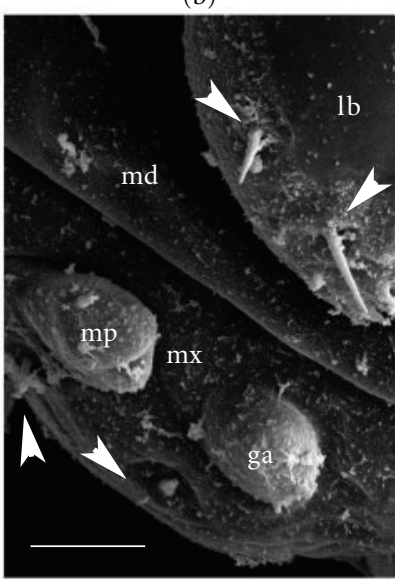

(c)

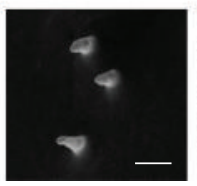

(e)

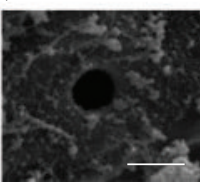

(f)

FIgURE 4: Fourth instar larva of Solenopsis saevissima worker. (a) Larva in side view. (b) Head capsule in full frontal view. (c) Frontal view of right mouthparts; lb: labrum; mx: maxilla; md: mandible; mp: maxillary palp; ga: galea; arrowheads: setaceous sensilla. (d) Lower mouthparts; md: mandibule; mx: maxilla; lm: labium. (e) Antennal sensilla (setaceous). (f) thoracic spiracle. Respective sizes of scale bars $(\mu \mathrm{m}): 200,100,10,15,5$, and 3 .

bifid $(0.075 \mathrm{~mm})$, bifid $(0.700 \mathrm{~mm})$, and simple $(0.055 \mathrm{~mm})$. Simple hairs predominate on ventral region of anterior somites, while bifid hairs predominate over the rest of the body (Figure 4(a)). "Food basket" area usually naked and without spines, except in larger specimens (not shown). Ten pairs of unornamented spiracles (Figure $4(\mathrm{f})$ ), the first slightly larger $(0.016 \mathrm{~mm})$ than others $(0.014 \mathrm{~mm})$, and last pair smallest $(0.100 \mathrm{~mm})$. Head capsule $0.370 \pm 0.020 \mathrm{~mm}$ wide $(n=13)$; subelliptical and with 20-30 hairs of two types: simple $(0.100-0.120 \mathrm{~mm})$ and bifid $(0.570 \mathrm{~mm})$, distributed as follows: seven or eight (rarely nine) hairs on occipital border, usually bifid (central hairs sometimes simple, see Figure 8), two or three hairs on each side of vertex (one usually bifid), two to four simple hairs on frons, five to seven simple hairs on each gena (Figure 4(b)). Antennae with three $1 \mu \mathrm{m}$-long setaceous (often basiconic) sensilla (Figure 4(e)). A pair of enclosed sensilla near base of mandibles (not shown). Clypeus poorly delimited from cranium and rectangular, with a row of four simple hairs at midheight (Figure 4(b)). Mouthparts: Labrum clearly delimited and roughly rectangular, slightly depressed mesad, $0.100-0.126 \mathrm{~mm}$ wide, with six basiconic sensilla and seven to eight setaceous sensilla on anterior face, ventral surface densely covered with rounded, spiny papillae (not shown). Maxilla roughly parabolic in shape, about $0.085 \mathrm{~mm}$ long and $0.047 \mathrm{~mm}$ wide, with two setaceous sensilla near base of palps (Figure $4(\mathrm{c})$ ). Galea paxiliform and $0.015 \mathrm{~mm}$ long, and maxillary palpus digitiform and $0.22 \mathrm{~mm}$ long, the first tipped with two setaceous sensilla and the latter with four sensilla, two basiconic, one setaceous, and one enclosed (Figures 4(c) and 4(d)). Mandibles ectatommoid in shape, heavily sclerotized, and stout $(0.100 \mathrm{~mm}$ long and $0.037 \mathrm{~mm}$ wide) with two apical teeth (Figure 4(d)) and two prominent subapical teeth followed by a long blade with two or three molar denticles (not shown). Labium rounded, about $0.8 \mathrm{~mm}$ wide; labial palps being simple elevations about $0.012 \mathrm{~mm}$ wide with four basiconic sensilla and one setaceous sensillum on top; labial surface below palps with two or three basiconic sensilla and one or two setaceous sensilla at varied positions; labial surface above the palps 


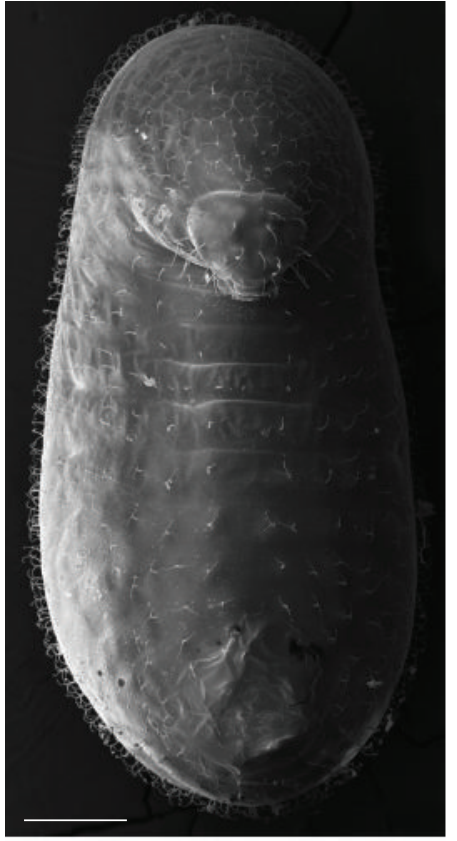

(a)

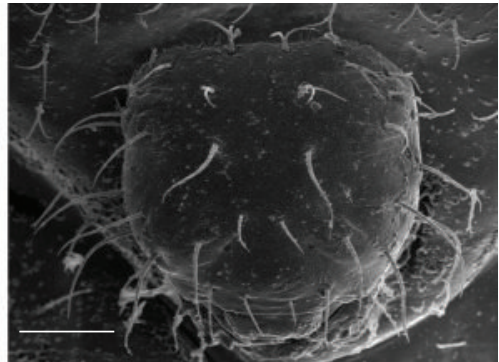

(b)

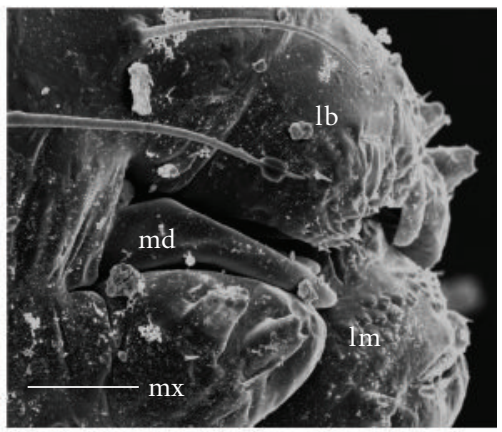

(c)

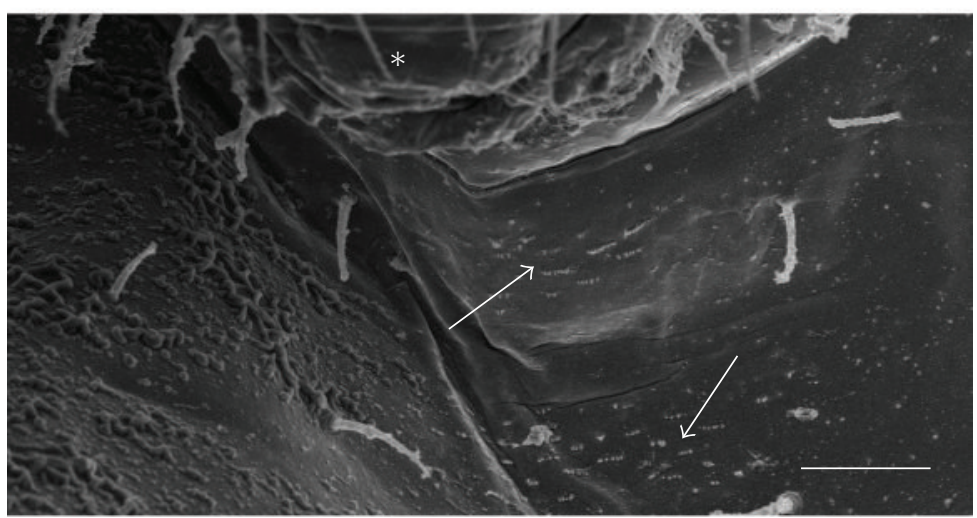

(d)

FIgURE 5: Last instar larva of Solenopsis saevissima gyne. (a) Body in frontal view. (b) Head capsule in full frontal view. (c) Mouthparts in oblique view; lb: labrum; md: mandibule; mx: maxilla; lm: labium. (d) Food basket area, asterisk: lower mouthparts; arrows: rows of spinules. Respective sizes of scale bars $(\mu \mathrm{m}): 400,100,50$, and 50.

endowed with sparse spines directed to the mouth entrance (Figure 4(d)). Opening of sericteries a horizontal slit about $0.035 \mathrm{~mm}$ long with an inconspicuous, enclosed sensillum by the end of each extremity (Figure 4(d)).

3.2.6. Reproductive Larvae (Figures 5 and 6). The reproductive larvae differed from worker larvae only in the last instar by their greater size and unique shape (compare Figures 4(a), $5(a)$, and 6(a)). Mature larvae (prepupae) of males measured $3.80-4.50 \mathrm{~mm}(n=12)$, with greatly engorged thoraxes (Figure 6(a)), and a whitish hue because of the development of a thicker integument (not shown). Mature larvae of gynes are longer (4.80-6.20 mm long) $(n=7)$ and swollen (Figure 5(a)). Also, greater body size results in a decrease in density of body hairs, thus reproductive larvae look distinctly less hairy than worker larvae.
A few morphological particularities were noted, probably deriving from their further increase in size, as described below.

3.2.7. Gyne Larvae (Figures 5(a)-5(d)). Antennal sensillae always setaceous, longer (not shown). Tentorial pits clearly discernible on cranium (Figure 5(b)). Labial surface under mouth entrance and posterior face of labrum densely spinulose (Figure 5(c)). Food basket area with rows of short spines (Figure 5(d)).

3.2.8. Male Larvae (Figures 6(a)-6(f)). First thoracic spiracle much larger than the remaining ones (inset of Figure 6(a)), peritreme opening with valve-like projections. Antennal sensillae always setaceous, longer; well-developed tentorial pits (Figures 6(b) and 6(d)). Maxillary palps slightly longer 


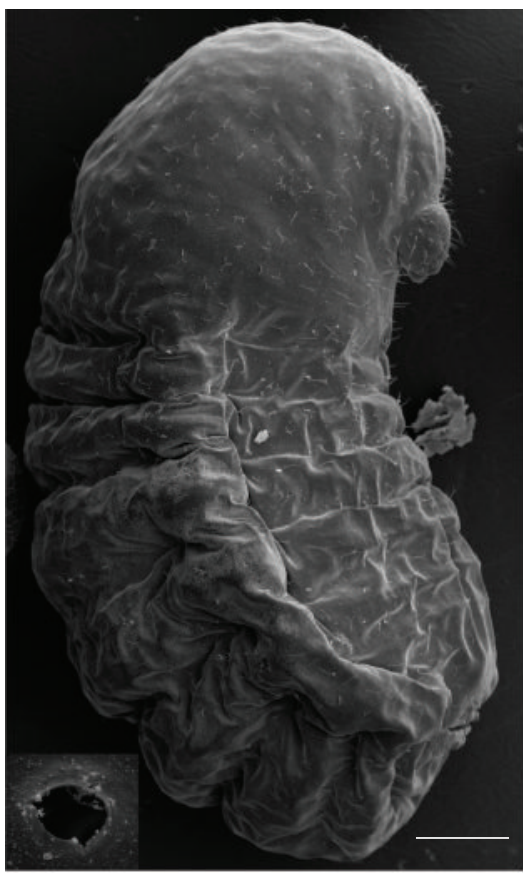

(a)

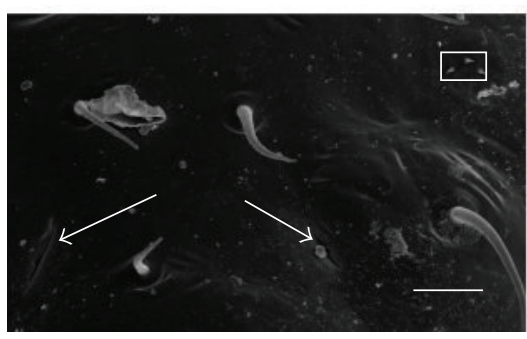

(d)

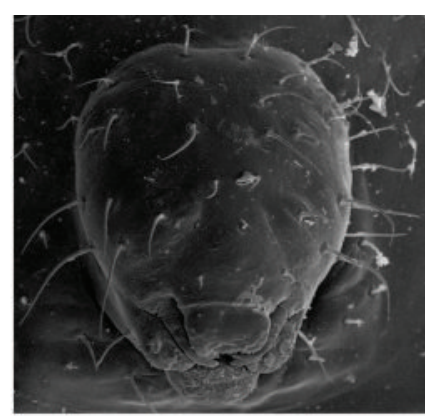

(b)

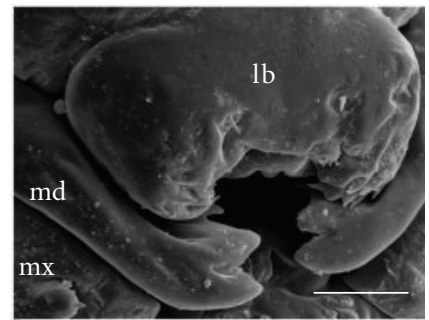

(c)

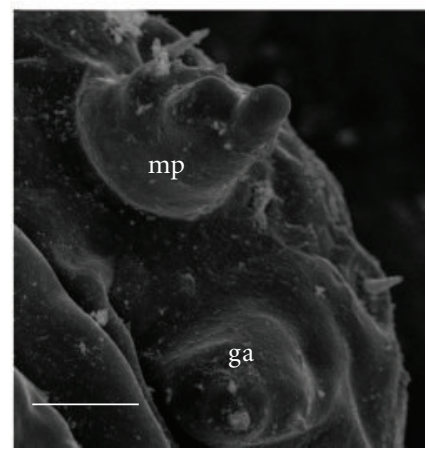

(e)

Figure 6: Last instar larva of male of Solenopsis saevissima. (a) Body in side view. (b) Head capsule in full frontal view. (c) Mouthparts in oblique view; lb: labrum; mx: maxilla; md: mandible. (d) Detail on frons of head capsule; arrows: tentorial pits; white box: left antenna. (e) Detail on right maxilla, showing maxillary palp (mp) and galea (ga). Respective sizes of scale bars ( $\mu \mathrm{m}): 400,100,20,30$, and 10.

and paxilliform, due to the presence of a well-developed, enclosed apical sensillum (Figures 6(c) and 6(e)). Similarly, galea with a distinct shape due to enlarged apical sensilla (Figure 6(e)).

3.2.9. Pupae (Figures $7(a)-7(c)$ ). Young pupae yellowish white, colour darkening with age as they mature into imagoes. Always exarate and without cocoons, yet pupal skin clearly discernible detached from the developing exoskeleton, particularly upon petiole (Figure $7(\mathrm{a})$ ). Worker pupae (Figure $7(\mathrm{a})$ ) varied $2.00-4.00 \mathrm{~mm}$ long $(n=29)$, while male pupae (Figure $7(\mathrm{~b}))$ averaged $4.20 \mathrm{~mm}(n=4)$, and gyne pupae (Figure 7(c)) measured 5.30-5.50 $\mathrm{mm}$ long $(n=6)$.

3.3. Comparisons with Other Species. From comparing numerous last instar larvae of $S$. saevissima with S. invicta and S. altipunctata, we were unable to pinpoint specific character states that could be used to differentiate between these species-that is, they are identical. All presented marked intraspecific variation in the morphology of head setae (i.e., "hairs" according with the terminology of the Wheelers), in which occipital and even vertexal hairs can be either simple, bifid, or at times 3-branched. Variations occurred among specimens from within the same nests and geographical locations. It is worth noting that a few specimens of $S$. saevissima and S. invicta had all head hairs simple, which is reminiscent of other species (read further notes in discussion).

Head hairs of specimens of S. geminata proved less variable than in other species, with occipital hairs usually bifid, sometimes 3-branched at random positions. Other characteristics were as described for S. saevissima.

\section{Discussion}

This is the first description of juvenile stages in S. saevissima, and the first larval description of a fire ant to include specimens of different castes and geographical locations. 


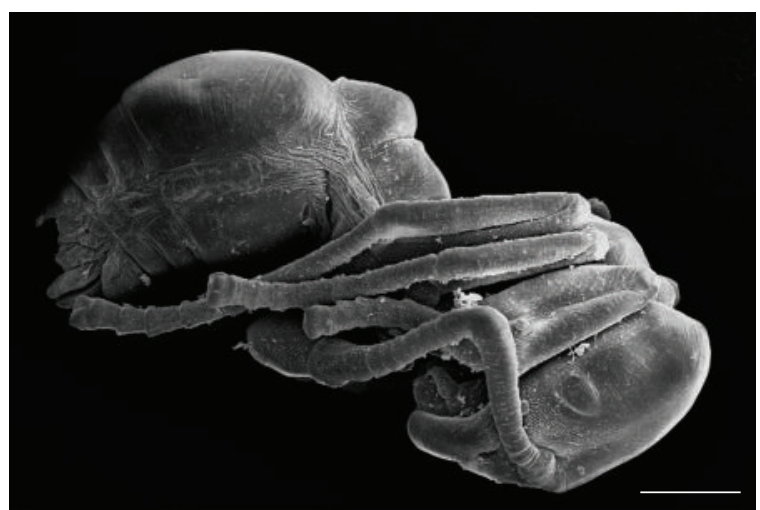

(a)

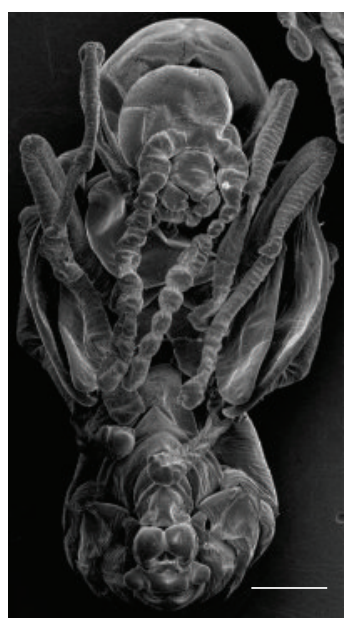

(b)

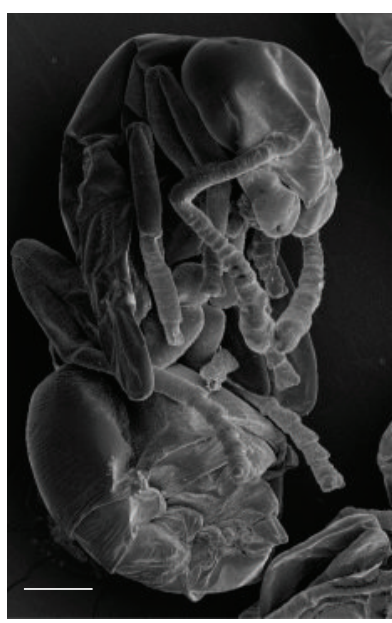

(c)
Figure 7: Pupae of major worker (a), male (b), and gyne (c) of Solenopsis saevissima. Respective sizes of scale bars $(\mu \mathrm{m}): 300,500$, and 500 .

Younger first- and second-instar larvae were always found in low frequencies in the collected nests, suggesting that they may last only for a few hours before moulting, or may reside in part of the nest not typically collected. This can only be determined by direct experimentation and observation of the duration of each larval instar.

The extensive similarities between reproductive and worker larvae were previously noted by G. C. Wheeler and J. Wheeler [2]. These authors reported only being able to distinguish reproductive from worker ant larvae using the last instar, as by this stage reproductive larvae are considerably larger. The distinct body shape acquired by the sexual larvae of males and gynes of $S$. saevissima makes sexual separation usually quite easy. It is certainly caused by the inner developing pupa. The greatly enlarged thoracic spiracle of male prepupae is probably related to intense metabolism in that somite (e.g., development of flight muscles?). This and the alterations in the integument of male larvae merit direct investigation.

The larval instars of $S$. invicta were previously described by O'Neil and Markin [8], who also presented descriptions of larvae of all castes, yet a later study by Petralia and Vinson

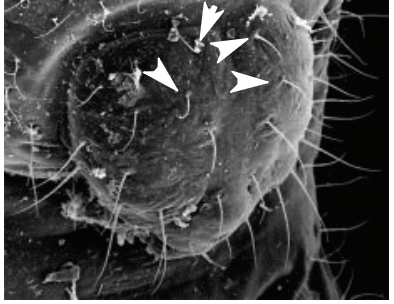

(a)

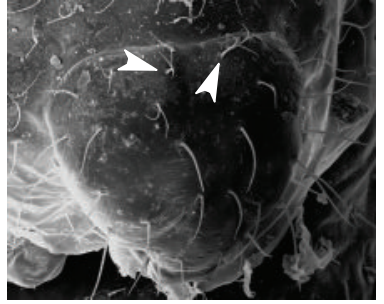

(b)

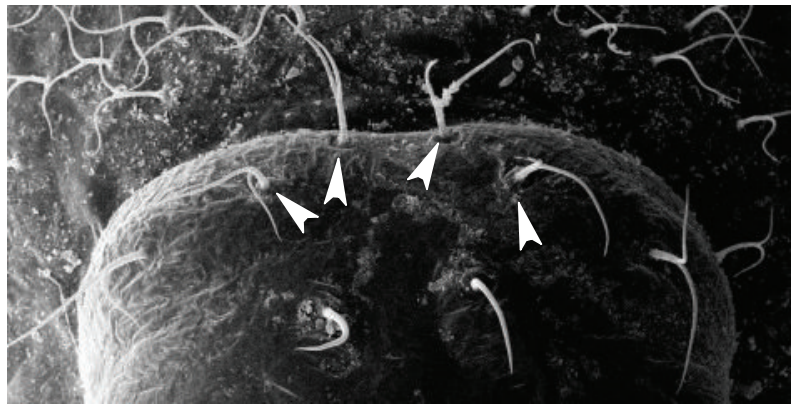

(c)

FIGURE 8: Head hairs (= setae) of fourth instar larvae from different fire ant species. Medial hairs of second row of vertex and occipital region are indicated with arrowheads. (a) Solenopsis saevissima with medial hairs simple (compare with Figures 4(b), 5(b), and 6(b), in which specimens had bifid hairs). (b) Solenopsis invicta with bifid hairs. (c) Solenopsis geminata with bifid hairs. Respective sizes of scale bars $(\mu \mathrm{m}): 80,100$, and 30 .

[9] added SEM images of all juvenile stages along with detailed descriptions, correcting several flaws in the original description by O'Neil and Markin [8]. Moreover, O'Neil and Markin [8] claimed that head widths of larvae of different castes were significantly different, but our observations do not support this assertion. In fact, it is clear from our results that Dyar's rule should be applicable for instar separation in fire ants using not only head width, but also mandible length and spiracle diameter, despite the pronounced worker polymorphism. Direct demonstration of this fact is warranted.

In a recent revision of morphological characters and phylogenetic relationships within fire ants, Pitts et al. [5] proposed the use of different sets of character states of the head setae (= hairs) of fourth instar larvae to facilitate species separation. Proposed head hairs to be used were those above the antennal level, individualized in the "first and second rows on vertex" and the "occipital row." The series of larval characters described by Pitts et al. [5] indicates that 4thinstar larvae of $S$. invicta would differ from those of $S$. saevissima and S. geminata in the morphology of the medial head hairs of the occipital region: in S. geminata and $S$. saevissima such hairs would always be bifid, yet larvae of S. invicta would vary in having simple or bifid hairs (for further details, see Pitts et al. [5]). These three species can alternatively be easily recognized based on other traits of major workers. In S. altipunctata, mature larvae would have the occipital row with inner hairs always bifid, with others 
simple; adult forms are, however, difficult to separate from $S$. invicta and S. saevissima without examining the queens.

However, in the present investigation we found considerable variation in the pattern of head hairs of mature larvae of S. saevissima from different nests from Rio de Janeiro, Minas Gerais and Bahia. As noted, some specimens even had all medial head hairs above antennal level simple, which should be diagnostic of Solenopsis richteri Forel [5]. By relying on the larval characters proposed by Pitts et al. [5], one would have mistaken the specimen of Figure 7(a) for Solenopsis megergates, many others for S. invicta, and a few for $S$. richteri. Our observations, thus, confirm the larval characters proposed by Pitts et al. [5] for S. invicta and S. geminata, but demonstrate that larvae of $S$. saevissima cannot be differentiated from other species because of extensive intraspecific (even intranest) variation. Also, similar intraspecific variation was observed with larvae of S. altipunctata. Similar marked intraspecific variation was also recently observed in larvae of Paratrechina longicornis Latreille [11], thus the phenomenon is most likely universal (among ants?).

As mentioned, subsequent to the study of Pitts et al. [5], Ross et al. [10] demonstrated the existence of cryptic species within S. saevissima. It should be noted that there is considerable molecular evidence that some of the other fire ant species might also include cryptic species [12]. It should be stressed that the present study was based on at least two different haplotypes of S. saevissima (samples from MG were not sequenced) and considerable intraspecific variation in this character state was detected in all of them, thus the morphology of head hairs is definitely not a reliable character for sorting between fire ant species given the present state of knowledge. We suspect that the samples examined by Pitts et al. [5] included only a few larvae of each species (the exact number of observations was not given), thus leading to biased conclusions.

In summary, the present description adds to the limited body of knowledge about juvenile stages of ants. Some of the observed traits found may have taxonomic importance (best suited for genus-level comparison), and probably reflect specializations in the life history of the group. We would not recommend the use of fire ant larvae for species identification in South America given the present state of knowledge, as one of the most common fire ant species, $S$. saevissima, exhibits considerable intraspecific variation that overlaps with other species, and there is significant evidence that this is also the case in closely related species.

\section{Acknowledgments}

The authors would like to thank Elliot Watanabe Kitajima and Francisco André Ossamu Tanaka (NAP/MEPA/ESALQ/ USP) for granting access to the electron microscopes, and Andrigo Monroe, Sandra Frances Fox Lloyd, and Maria Helena dos Santos for assistance in the field in locating fire ant nests. Dietrich Gotzek provided useful tips in the molecular identification of specimens and discussion insights. Several anonymous reviewers contributed useful critiques; Scott E. Solomon kindly polished the narrative in the final version of the manuscript.

\section{References}

[1] T. Finlayson, "A classification of the subfamily Pimplinae (Hymenoptera: Ichneumonidae) based on final-instar larval characteristics," The Canadian Entomologist, vol. 99, pp. 1-8, 1975.

[2] G. C. Wheeler and J. Wheeler, "Ant larvae: review and synthesis," Memories of the Entomological Society of Washington, vol. 7, pp. 1-108, 1976.

[3] T. R. Schultz and R. Meier, "A phylogenetic analysis of the fungus-growing ants (Hymenoptera: Formicidae: Attini) based on morphological characters of the larvae," Systematic Entomology, vol. 20, pp. 337-370, 1995.

[4] B. Bolton, G. Alpert, P. S. Ward, and P. Naskrecki, Bolton Catalogue of Ants of the World: 1758-2005, Harvard University Press, Cambridge, Mass, USA, 2006.

[5] J. P. Pitts, M. C. J. Hugh, and K. G. Ross, "Cladistic analysis of the fire ants of the Solenopsis saevissima species-group (Hymenoptera: Formicidae)," Zoologica Scripta, vol. 34, no. 5, pp. 493-505, 2005.

[6] J. C. Trager, "A revision of the fire ants of the Solenopsis geminata group (Hymenoptera: Formicidae: Myrmicinae)," Journal of the New York Entomological Society, vol. 99, pp. 141198, 1991.

[7] G. C. Wheeler and J. Wheeler, "The ant larvae of the myrmicine tribe Solenopsidini," The American Midland Naturalist, vol. 54, pp. 119-141, 1955.

[8] J. O’Neal and G. P. Markin, "The larval instars of the imported fire ant Solenopsis invicta (Hymenoptera: Formicidae)," Journal of the Kansas Entomological Society, vol. 48, pp. 141-151, 1975.

[9] R. S. Petralia and S. B. Vinson, "Developmental morphology of larvae and eggs of the imported fire ant, Solenopsis invicta," Annals of the Entomological Society of America, vol. 72, pp. 472484, 1979.

[10] K. G. Ross, D. Gotzek, M. S. Ascunce, and D. D. Shoemaker, "Species delimitation: a case study in a problematic ant taxon," Systematic Biology, vol. 59, no. 2, pp. 162-184, 2010.

[11] E. G. P. Fox, D. R. Solis, C. M. Jesus, O. C. Bueno, A. T. Yabuki, and M. L. Rossi, "On the immature stages of the crazy ant Paratrechina longicornis (Latreille 1802) (Hymenoptera: Formicidae)," Zootaxa, no. 1503, pp. 1-11, 2007.

[12] K. G. Ross, M. J. B. Krieger, L. Keller, and D. D. Shoemaker, "Genetic variation and structure in native populations of the fire ant Solenopsis invicta: evolutionary and demographic implications," Biological Journal of the Linnean Society, vol. 92, no. 3, pp. 541-560, 2007. 

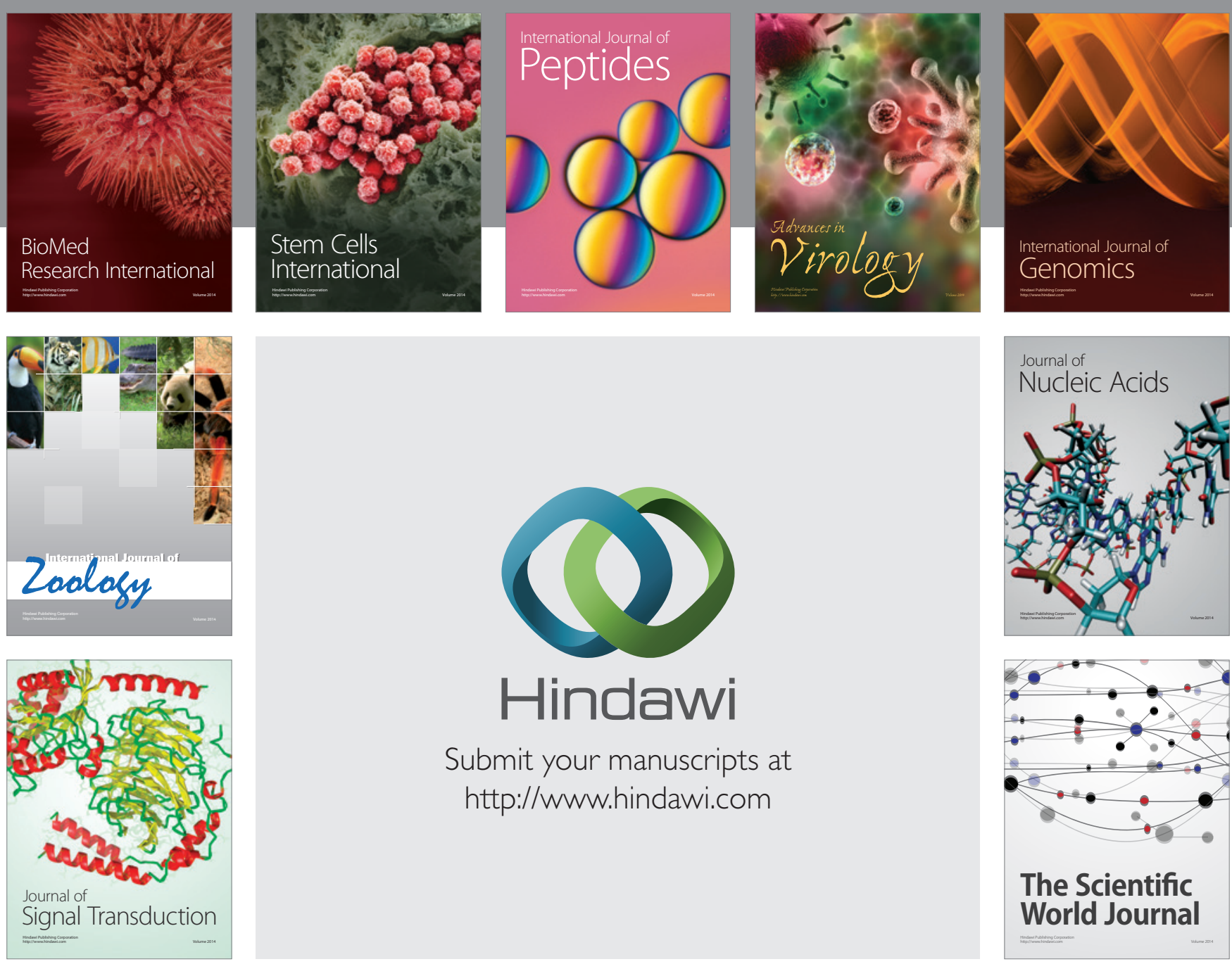

Submit your manuscripts at

http://www.hindawi.com
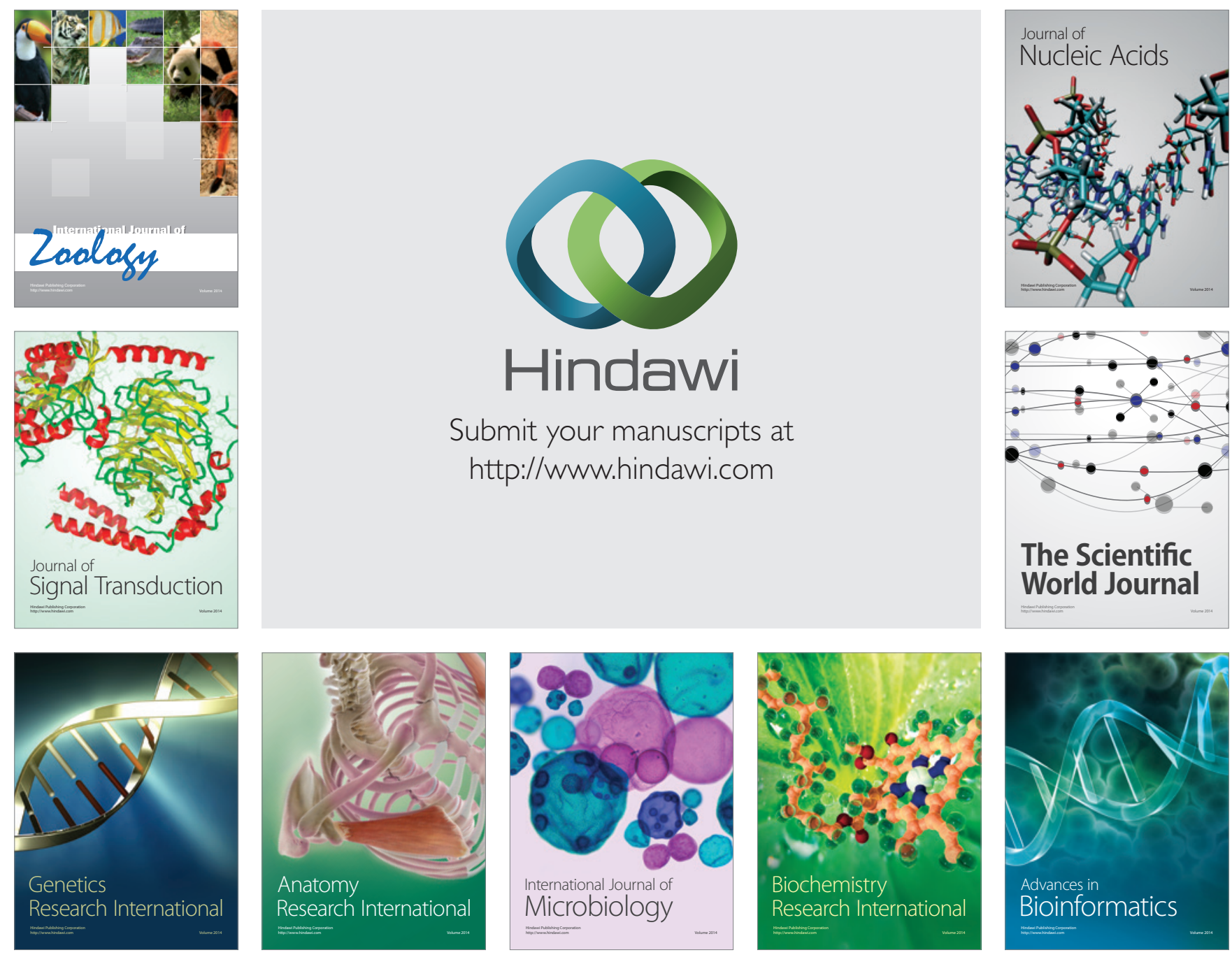

The Scientific World Journal
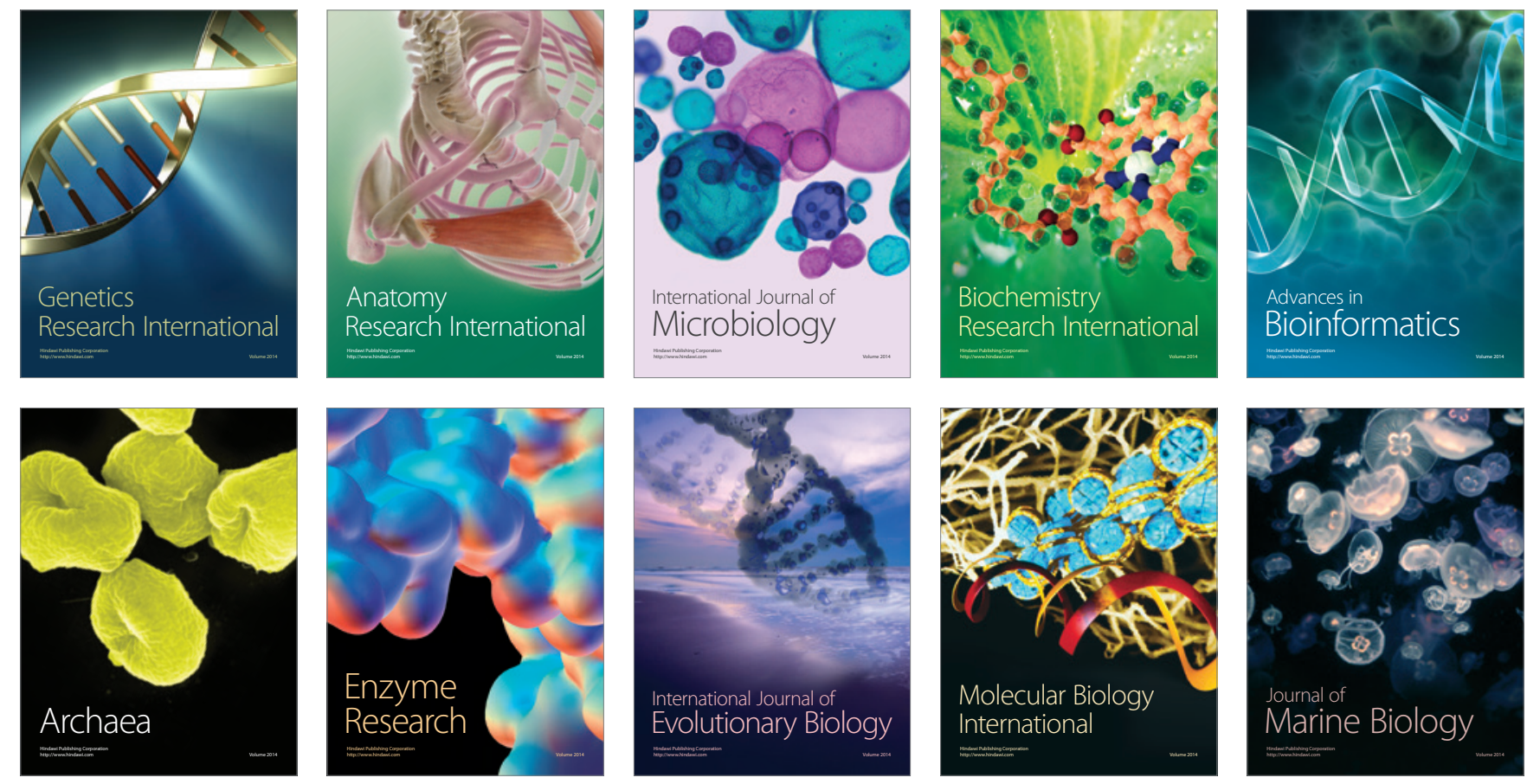